\title{
Organização estrutural da casca de Persea major Kopp (Lauraceae)
}

\author{
Leila Teresinha Maranho ${ }^{1,2}$, Karla Heloise Preussler ${ }^{1}$ e Ledyane Dalgallo Rocha ${ }^{1}$
}

Recebido em 8/05/2008. Aceito em 6/10/2008

\begin{abstract}
RESUMO - (Organização estrutural da casca de Persea major Kopp (Lauraceae)). O presente estudo foi desenvolvido com o objetivo de contribuir ao conhecimento da estrutura da casca de Persea major Kopp (Lauraceae), espécie nativa da América do Sul. No Brasil, é conhecida, popularmente, como "pau de andrade" e utilizada na cultura tradicional na cicatrização dos ferimentos. A análise da casca foi feita usando microscopia de óptica. A casca se distingue, principalmente, pelo tipo e distribuição dos tecidos esclerenquimáticos e a presença de células oleíferas e mucilaginosas. As características encontradas na estrutura da casca desta espécie mostram grande importância para a identificação e servem como parâmetros no controle de qualidade. Estas células oleíferas e mucilaginosas com uma distribuição restrita nas dicotiledôneas constituem uma característica taxonômica e diagnóstica particularmente valiosa.
\end{abstract}

Palavras-chave: anatomia de casca, anatomia vegetal, Lauraceae, Persea major

\begin{abstract}
Structural organization of Persea major Kopp bark (Lauraceae)). The study was undertaken to increase our knowledge of bark structure of Persea major Kopp (Lauraceae), a native specie from South America. In Brazil, it is known as "pau de andrade" and is used by traditional cultures to heal injuries. This analysis was done by light microscopy. The bark is distinguished mainly by the type and distribution of sclerenchymatic tissues, and the presence of oil and mucilage cells. The characteristics found in the bark anatomy of this species are of great importance for identification purposes and as parameters in quality control. These oil and mucilage cells have a restricted distribution in the dicotyledons and constitute a particularly valuable taxonomic and diagnostic feature.
\end{abstract}

Key words: bark anatomy, Lauraceae, Persea major, plant anatomy

\section{Introdução}

As pesquisas que visam à compreensão de caracteres do lenho tornam-se instrumentos cada vez mais importantes para o esclarecimento de questões taxonômicas, evolutivas e ecológicas. Associados a estes estudos surgem, um pouco mais tarde, aqueles sobre a anatomia da casca, que apresentam como objetivo principal, complementar os dados obtidos a partir de estudos realizados com o lenho.

Esses estudos, em geral, são auxiliares para a identificação e separação de espécies, como comprovado por diversos autores (Richter 1981; Trockenbrodt \& Parameswaran 1986; Angyalossy-Alfonso \& Richter 1991), embora seja possível constatar que os estudos anatômicos de casca são escassos quando comparados com os de lenho.

A partir de análises do xilema secundário de duas espécies de leguminosas, Teixeira \& Gabrielli (2000), afirmam que a anatomia da madeira é válida na identificação de espécies e que esta linha de pesquisa encontra-se consolidada. Como exemplo, pode-se citar o estudo realizado por Oliveira et al. (2001), que possibilitou a segregação de três espécies do gênero Nectandra (Lauraceae), pelas características observadas no lenho destes vegetais.

Em alguns casos, no entanto, a organização estrutural do xilema secundário pode ser semelhante para muitas espécies, não podendo ser utilizada como único parâmetro para a segregação taxonômica.

Por isso, Soffiatti \& Angyalossy-Alfonso (1999), que realizaram estudos anatômicos da casca de duas duas espécies de Eugenia, afirmam que o investimento em estudos sobre a anatomia da casca permite a obtenção de informações taxonômicas, além de dados acerca da evolução e ecologia. Segundo as autoras, a casca apresenta uma quantidade de subsídios distintivos superior àquelas que são obtidas após a análise do lenho.

De acordo Trockenbrodt (1990) e Richter et al. (1996), casca é o termo usado para designar todos os tecidos externos ao câmbio vascular, compreendendo uma considerável variedade de tecidos e a estrutura

\footnotetext{
1 Universidade Positivo, Curso de Ciências Biológicas, Rua Professor Pedro Viriato Parigot de Souza 5300, Bairro Campo Comprido 81280-330 Curitiba, PR, Brasil

2 Autora para correspondência: maranho@up.edu.br
} 
anatômica é muito diversificada nas diferentes espécies. Segundo Metcalfe \& Chalk (1988), estes tecidos incluem o floema secundário e a periderme, que no caso de existirem várias camadas geram o ritidoma.

Segundo Richter et al. (1996), a estrutura anatômica do floema secundário varia em diferentes profundidades da casca devido às transformações ocorridas na forma, vitalidade, arranjo e conteúdo de suas células. Estas transformações são necessárias para manter a integridade da casca, já que os tecidos floemáticos são externos ao câmbio vascular e a circunferência da casca precisa aumentar continuamente para acompanhar o crescimento em diâmetro do xilema.

Os primeiros estudos sobre casca em ecossistemas florestais intertropicais remontam a década de $50 \mathrm{com}$ trabalhos de Wood (1952), Rosayro (1953), Beard (1953) e, mais tarde, os estudos de Roth (1969), Jiménez Saa (1967), Outer (1972), Ghouse et al. (1979), Roth (1981), Iqbal \& Ghouse (1982), Baraja-Morales \& PerezJiménez (1990), Yunus et al. (1990) e Roth \& Jiménez de Bolsón (1997) valorizaram a anatomia da casca por se tratar de uma nova ferramenta para o conhecimento de árvores. Tais autores abordam a padronização de critérios para a descrição anatômica da casca.

Dentre as espécies incluídas na família Lauraceae, cerca de 3.000 são lenhosas e se distribuem, principalmente, nas florestas centro e sul-americanas (Metcalfe 1987; Rohwer 1993; Van der Werff \& Richter 1996). Grande parte destas espécies contém substâncias aromáticas, possuem madeira, óleos essenciais e frutos comestíveis, o que torna as mesmas importantes economicamente.

A família Lauraceae possui ainda importância fitossociológica, o que é justificado pela sua ampla distribuição, bem como pela representatividade das suas espécies (Rizzini 1971; Gottlieb 1972; Klein 1974). Nos remanescentes de Floresta Atlântica localizados no Estado do Paraná, por exemplo, as espécies que apresentam as maiores riquezas florísticas pertencem à família Lauraceae. Ainda é importante ressaltar que, apesar da importância desta família, as espécies que a compõe são muito semelhantes morfologicamente, o que dificulta a caracterização específica (Record \& Mell 1924; Record \& Hess 1942; Castiglioni 1951; 1962).

As semelhanças existentes nos caracteres florais resultam em uma problemática na taxonomia da família, são partes vegetais amplamente utilizados para confecção de chaves de identificação, bem como para os estudos taxonômicos de Lauraceae (Van der Werff 1991). Devido a estas dificuldades, Van der Werff \& Richter (1996) sugeriram que os estudos taxonômicos na família sejam realizados através da combinação de caracteres anatômicos da casca, do lenho e do tipo de inflorescência.
A casca é de grande importância na identificação de árvores vivas, e o estudo de sua estrutura vem despertando cada vez mais interesse por contribuir enormemente para a distinção entre espécies semelhantes. Os estudos para reconhecer espécies do gênero Persea são escassos, desta forma o presente trabalho foi realizado com objetivo de obter dados que contribuam para a compreensão das características anatômicas da casca de Persea major Kopp e da própria taxonomia do gênero Persea.

\section{Material e métodos}

A coleta do material foi realizada em um fragmento de Floresta Ombrófila Mista (Floresta com Araucária) localizada em Curitiba no limite com o município de São José dos Pinhais, Paraná, Brasil, próximo às coordenadas geográficas $25^{\circ} 35^{\prime} 1,2^{\prime}$ 'S e $49^{\circ} 15^{\prime} 43,7^{\prime}$ 'W e em uma altitude de aproximadamente 900 m.s.m.

O estudo macroscópico foi realizado em material fresco, diretamente no campo e a vista desarmada ou com uma lupa de mão. A cor da madeira foi determinada com a utilização da Tabela de Cores para Tecidos Vegetais (Munsell Color 1977).

Para o estudo microscópico o material (madeira e casca) foi coletado de três indivíduos adultos, com perímetro altura do peito (PAP) entre 65 e $83 \mathrm{~cm}$. O PAP foi obtido com o auxílio de fita métrica e estas mensurações foram realizadas para padronizar os indivíduos dos quais foram obtidas as amostras. Estas foram coletadas à altura do peito (AP), aproximadamente 1,3 m do solo, com auxílio de formão. A fixação foi realizada no próprio local de coleta utilizando-se FAA 70 (Johansen 1940), posteriormente, armazenando em etanol $70 \%$ até o processamento final (Berlyn \& Miksche 1976). As exsicatas encontram-se depositadas no Herbário da Universidade Federal do Paraná (UPCB), sob número 43562.

Para a confecção do laminário foram obtidos corpos de prova a partir do material previamente fixado. Estes foram amolecidos por cozimento em água e glicerina (Ferreirinha 1958), durante um período de cinco dias, e seccionados nos sentidos transversal, longitudinal radial e longitudinaltangencial (Franklin 1945).

O seccionamento foi realizado em micrótomo de deslize, obtendo-se secções isoladas de $20 \mu \mathrm{m}$ de espessura. Procedeu-se, então, à dupla coloração utilizando Safrablau (Kraus \& Arduim 1997).

Após a coloração fez-se a desidratação das secções em série alcoólica etílica ascendente. Como meio de montagem empregou-se resina sintética (Entellan $®$ ).

Para os testes histoquímicos, secções nos três planos foram tratadas com os seguintes reagentes: azul 
de metileno (Stevens 1916) para mucilagem; lugol (Berlyn \& Miksche 1976) indicado para amido; floroglucinol acidificado (Foster 1949) para lignina e Sudam III (Sass 1951) para corar substâncias graxas. Fotomicroscópio (Olympus - BX 41) foi utilizado para obtenção das ilustrações,sendo as escalas obtidas nas mesmas condições das fotos. As descrições obedeceram às recomendações de Trockenbrodt (1990), Junikka (1994) e Richter et al. (1996).

\section{Resultados e discussão}

A casca possui cerca de $1,5 \mathrm{~cm}$ de espessura; a sua superfície externa varia de pardo-claro acinzentado a marrom-acastanhado escuro, com manchas cinza-claras, esverdeadas e amareladas em função da presença de fungos e liquens, e na superfície interna é marrom-acastanhado claro, com pequenas manchas esbran-quiçadas. A casca de Persea major é dividida anatomicamente em felema, felogênio e feloderme, formando a periderme; bainha esclerenquimática; floema colapsado e floema não colapsado (Fig. 1). A periderme é constituída por felogênio com espessura aproximada de $1000 \mu \mathrm{m}$ e formado por cerca de 25 camadas de células dispostas compactamente e com paredes celulares fortemente suberizadas (Fig. 2a-b). Seqüencialmente, são observados o felogênio e a feloderme (Fig. 2a-b), sendo, o primeiro formado por células de paredes finas, alongadas no sentido tangencial e, a segunda, incipiente, formada por 4-5 camadas de células parenquimáticas de paredes delgadas (Fig. 2a). O floema caracteriza-se pela alternância de células vivas com células esclerificadas, as quais se distribuem em grupos ou em faixas (Fig. 2b-c).

O floema colapsado é caracterizado pela inatividade funcional dos elementos crivados, dilatação ou desorientação progressiva dos raios e alterações diversas em vários tipos de células (Fig. 2d ). O tecido de dilatação é derivado predominante do parênquima radial. Os raios dilatados confundem-se com as células parenquimáticas axiais, também dilatadas, formando um tecido de arranjo desordenado, denominado de pseudocórtex (Fig. 2b, 2d). Roth (1981) observou essa mesma característica na casca de duas espécies sul-americanas de Eugenia. Angyalossy-Alfonso (1983) afirma que, nas espécies de Eucalyptus por ela estudadas, esse tecido é formado pelo parênquima axial.

Na região mais externa do floema, forma-se um cilindro de células parenquimáticas que aos poucos sofrem esclerificação até originar uma bainha esclerosada, de 2-10 células de espessura, composta por células pétreas (Fig. 1, 2a).

Externamente à bainha esclerenquimática, ocorrem restos de parênquima cortical. A esclerificação dos raios parenquimáticos que atravessam ou são adjacentes às esclereídes foi observada em espécies de outras famílias (Parameswaran \& Liese 1972; Richter 1981; Van Wyk 1985; Angyalossy-Alfonso \& Richter 1991). Richter (1981) ao analisar a casca de espécie do gênero Aniba, descreveu os raios floemáticos como, na maioria, bisseriados e, em algumas espécies, dilatados na região mais externa.

No floema não colapsado, os elementos de tubo crivado são predominantemente solitários, ativos e não colapsados (Fig. 2e), placas crivadas simples, de orientação oblíqua, as áreas crivadas laterais são abundantes e as células companheiras estão presentes (Fig. 2e, 3a). Os raios seguem uma orientação radial bem definida e não apresentam crescimento de dilatação, são heterocelulares, com corpo formado por células procumbentes e as margens por duas camadas de células quadradas e eretas; multisseriados, com 3-4 células de largura (Fig. 2f, 3b).

As fibras são representadas por elementos esclerificados alongados, tendo um lume bem reduzido, podem estar associadas às esclereídes ou isoladas (Fig.

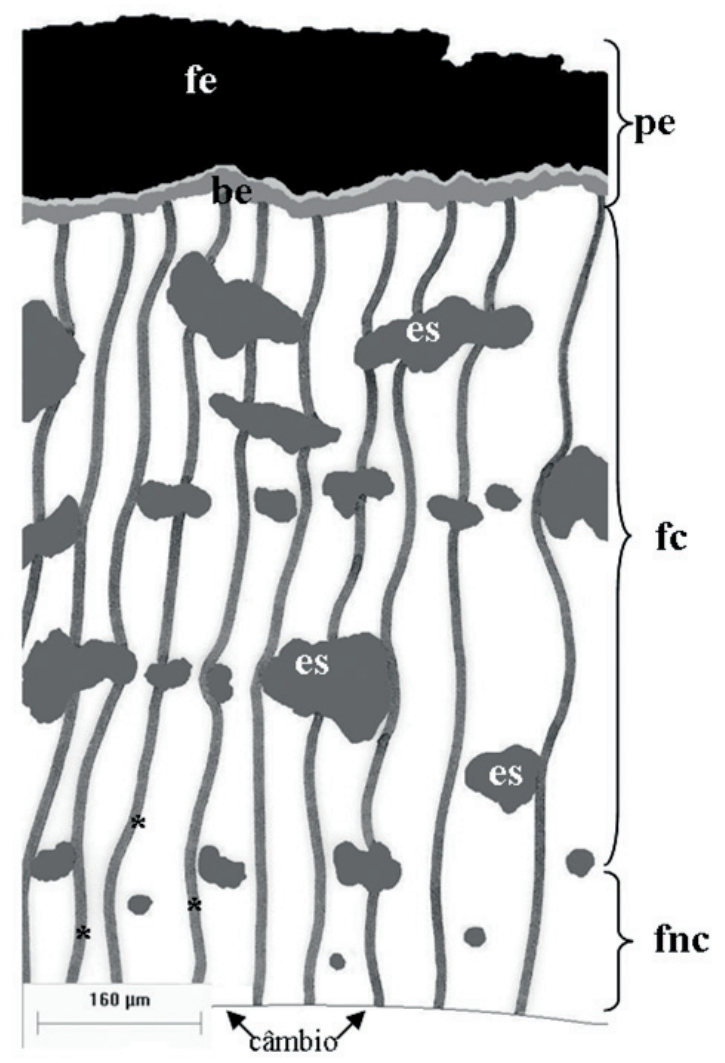

Figura 1. Diagrama da casca de Persea major Kopp em secção transversal. (fe: felema; be: bainha esclerenquimática; es: esclereídes; *: raios parenquimáticos; pe: periderme; fc: floema colapsado; fnc: floema não colapsado). 

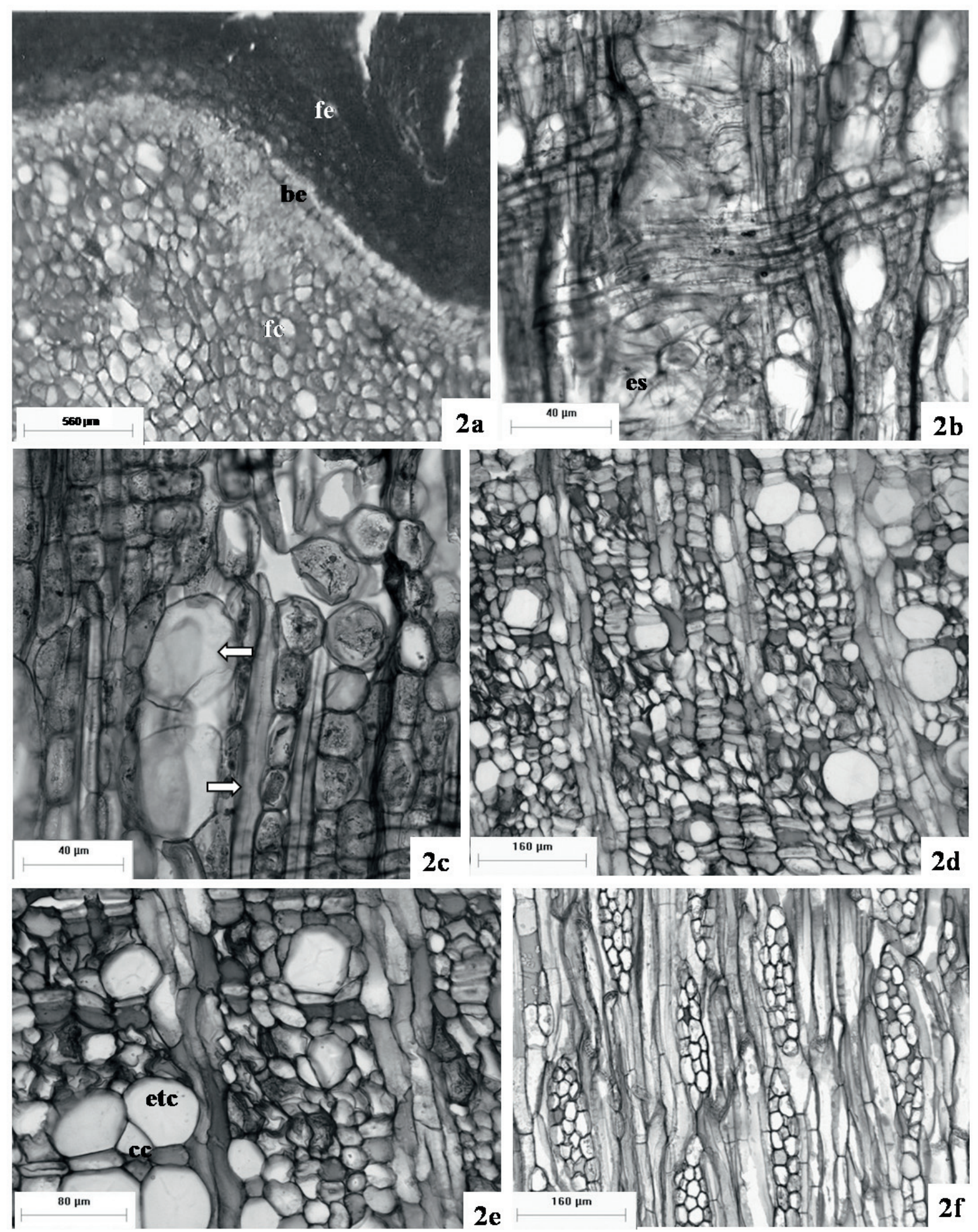

Figuras 2a-f. a. Secção transversal da casca de Persea major Kopp demonstrando a região do felema (fe), bainha esclerenquimática (be) e início do floema colapsado (fc). b. Secção longitudinal radial da casca de $P$. major, alternância de células vivas com células esclerificadas (es). c. Secção longitudinal radial da casca de $P$. major, alternância de células vivas com células esclerificadas $(\rightarrow)$ e célula mucilaginosa $(\leftarrow)$. d. Aspecto geral da região do floema colapsado em secção transversal da casca de $P$. major. e. Secção transversal da casca de $P$. major, detalhe dos elementos de tubo crivado (etc) e suas respectivas células companheiras (cc). f. Secção longitudinal tangencial da casca de $P$. major. 
2a, 2c, 3c) concordando com as observações feitas por Richter (1981) e Metcalfe (1987). Metcalfe \& Chalk (1988) ressaltam que as fibras do floema secundário são de considerável importância taxonômica e que, em alguns gêneros de Lauraceae, apresentam freqüência e distribuição com notável uniformidade. As esclereídes ocorrem agregadas (Fig. 3c), formando faixas tangenciais, diferenciam-se próximo à região cambial, são polimorfas, com paredes polilameladas e pontoações evidentes (Fig. 3d).

$\mathrm{O}$ parênquima axial apresenta-se em série e com grande acúmulo de grãos de amido. Segundo Esau (1964), o esclerênquima é um dos tipos celulares mais comumente encontrados no floema secundário. Parameswaran (1980) e Trockenbrodt (1990) citam que as esclereídes originam-se a partir da diferenciação de células parenquimáticas, são de fácil reconhecimento e podem apresentar várias formas. Na casca de Persea major ocorrem esclereídes curtas e alongadas com paredes muito espessadas, polilameladas e muitas pontoações (Fig. 3c-d). Trockenbrodt (1990) cita que o aparecimento das esclereídes parece estar relacionado com o processo de maturação da árvore.

Idioblastos, com mucilagem e óleo, são muito comuns no floema secundário de Persea major (Fig. 2c). Células especializadas, do parênquima axial ou radial de algumas famílias de dicotiledôneas, contêm óleo ou mucilagem. Tais células são conhecidas como oleíferas ou mucilaginosas, dependendo da natureza química de seus conteúdos. De acordo com Vattimo (1968), Santos \& Oliveira (1988) e Fahn (1990), os óleos essenciais e as mucilagens em Lauraceae encontram-se depositados em idioblastos secretores que, em contraste com as estruturas multicelulares, são células individuais, distinguindo-se das demais pelo conteúdo, forma, tamanho e espessamento da parede. Essas estruturas são consideradas homólogas, no entanto, alguns autores, como Fahn (1990) e Bakker et al. (1992), sugerem que um tipo desenvolve-se a
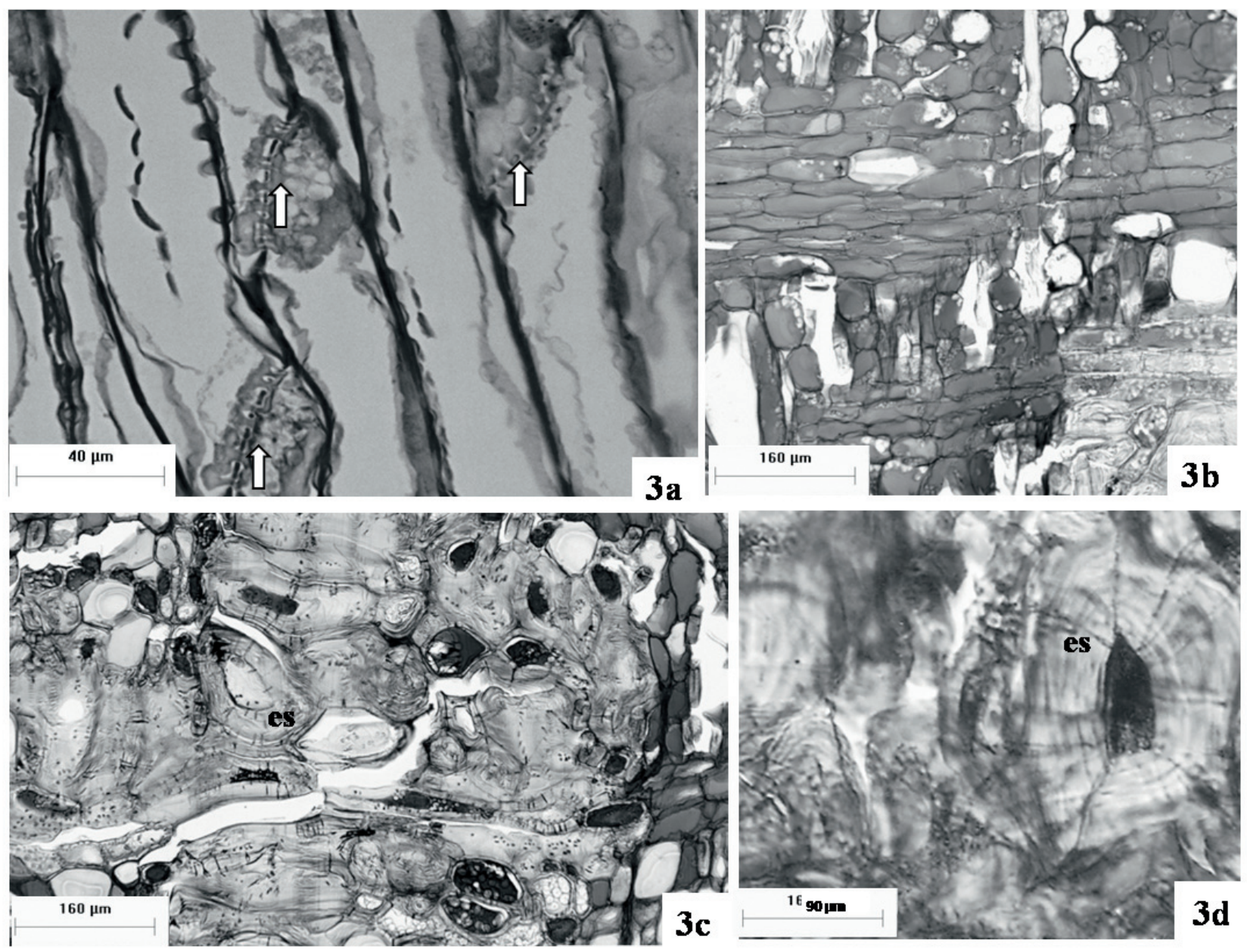

Figuras 3a-d. a. Secção longitudinal tangencial da casca de Persea major Kopp, detalhe das placas crivadas oblíquas ( $\uparrow$ ). b. Secção longitudinal radial da casca de $P$. major. c. Secção longitudinal radial da casca de $P$. major, detalhe das esclereídes (es). d. Secção longitudinal radial da casca de $P$. major, detalhe das esclereídes com paredes celulares polilameladas (es). 
partir do outro. Bakker et al. (1992), através de uma reinvestigação estrutural, confirmaram que células de Cinnamomum Schaeffer contêm misturas lipofílicas e mucilaginosas, implicando em um desencadeamento posterior em categorias distintas de células com óleo volátil ou mucilagem.

Metcalfe \& Chalk (1988) listaram 16 famílias de dicotiledôneas, incluindo Lauraceae, caracterizadas pela presença de células oleíferas. Estes mesmos autores citam, ainda, que as células oleíferas, com distribuição restrita em dicotiledôneas, constituem uma particularidade taxonômica e de diagnóstico muito valioso à família Lauraceae. Richter (1981) relata a existência dessas células em 40 gêneros de Lauraceae. Este mesmo autor cita que, em relação às células mucilaginosas, o que se observa é a ocorrência em poucos gêneros de Lauraceae. Farago et al. (2004) demonstram a existência de idioblastos formados por células secretoras de substâncias lipofílicas e mucilaginosas na casca de Ocotea puberula Rich.

Com a realização do presente estudo, pode-se verificar que a anatomia da casca é uma ferramenta capaz de fornecer dados peculiares e que podem auxiliar a caracterização específica, devendo ser explorada em estudos que visem esclarecer questões taxonômicas. Além disto, foi possível contribuir com informações acerca das características anatômicas de Persea major, uma vez que os estudos com espécies do gênero Persea ainda são escassos.

\section{Agradecimentos}

As autoras agradecem à Universidade Positivo, Curso de Ciências Biológicas e Mestrado Profissional em Gestão Ambiental pelo apoio.

\section{Referências bibliográficas}

Angyalossy-Alfonso, V. \& Richter H.G. 1991. Wood and bark anatomy of Buchenavia Eichl. (Combretaceae). IAWA Bulletin 12: 123-141.

Angyalossy-Alfonso, V. 1983. Caracterização anatômica da madeira e casca das principais espécies de Eucalyptus do Estado de São Paulo. Silvicultura 28: 720-725.

Bakker, M.E.; Gerritsen, A.F. \& Schaaf, P.J. 1992. Leaf anatomy of Cinnamomum Schaeffer (Lauraceae) with specil reference to oil and mucilage cells. Blumea 37: 1-70.

Baraja-Morales, J. \& Pérez-Jiménez, L.A. 1990. Manual de Identificación de árboles de selva baja mediante cortezas. México, Universidad Autónoma de México.

Beard, C.F.S. 1953. Key for the identification of the more important trees of Tobago on characters of bark and blaze. Emp. For. Journal 23: 34-36.

Berlyn, G.P. \& Miksche, J.P. 1976. Botanical microtechnique and cytochemistry. Iowa, Iowa University.

Castiglioni, J.A. 1951. Lauraceas Argentinas (1). I. Genero Nectandra. Boletin de la Sociedad Argentina de Botanica
4: $67-94$.

Castiglioni, J.A. 1962. El leño secondario de las especies argentinas de Nectandra. Revista de Investigaciones Forestales 3: 1-15 +5 plates.

Esau, K. 1964. Structure and development of the bark in dicotyledons. In: The formation of wood in forest trees. New York, M.H. Zimmerman (ed.). Academic Press.

Fahn, A. 1990. Plant Anatomy. Oxford, Pergamon.

Farago, P.V.; Duarte, M.R.; Alquini, Y. \& Nakashima T. 2004. Análise farmacognóstica das cascas de Ocotea puberula (Rich.) Nees, Lauraceae. Revista Brasileira de Farmácia 85: 23-26.

Ferreirinha, M.P. 1958. Elementos de anatomia de madeiras folhosas portuguesas. Lisboa. Memórias da Junta de Investigações do Ultramar Ed. 3. Segunda série.

Franklin, L. 1945. Preparation of thin sections synthetic resins and wood. Resin composites, and a new macerating method for wood. Nature 155: 51.

Foster, A.S. 1949. Practical plany anatomy. New York, Van Nostrand.

Ghouse, A.; Iqbal, M.; Siddiqui, F. \& Jamal, A. 1979. Taxonomic significance of sclerenchyma distribution in the secondary phloem of some Indian Tropical Trees. Feddes Repertorium 90: $173-178$.

Gottlieb, O.R. 1972. Review article chemosystematics of the Lauraceae. Phytochemistry 11: 1537-1570.

Iqbal, M. \& Ghouse, A.K.M. 1982. Comparative bark feature of some arid zone species of Acacia and Prosopis. Phytomorphology 32: 373-380.

Jiménez Saa, J.H. 1967. La identificación de los árboles tropicales utilizando características del tronco y la corteza. I.I.C.A. (Instituto Interamericano de Ciencias Agrícolas de la O.E.A. Centro de Large Trees. Meded. Landbouwhogesch. Wageningen 72: 1-73.

Johansen, D.A. 1940. Plant microtechnique. New York, Mc Graw Hill Book.

Klein, R.M. 1974. Importância e fidelidade das Lauraceae na "Formação Araucária" do Estado de Santa Catarina. Insula 7: $1-19$.

Kraus, J.E. \& Arduim, M. 1997. Manual básico de métodos em morfologia vegetal. Rio de Janeiro, Edur.

Metcalfe, C.R. 1987. Anatomy of the Dicotyledons. 2. ed. Oxford, Claredon Press.

Metcalfe, C.R. \& Chalk, L. 1988. Anatomy of the dicotyledons. vol. II. Wood structure and conclusion of the general introduction. 2. ed. Oxford, Clarendon Press.

Munsell Color. 1977. Munsell color charts for plant tissues. Baltimore, Macbeth Division of Kollmorgen Instruments Corporation.

Oliveira, C.W.; Callado, C.H. \& Marquete, O. 2001. Anatomia do lenho de espécies do gênero Nectandra Rol. ex Rottb. (Lauraceae). Rodriguesia 52: 125-134.

Outer, R.W. 1972. Tentative determination key to 600 trees, shrubs and climbers from the Ivory Coast, Africa, mainly based on characters of the living bark, besides the rhytidome and the leaf. Wageningen, Agricultural University, Department of Botany.

Parameswaran, N. \& Liese, M. 1972. Studies in bark anatomy. IAWA Bulletin 3: 12-16.

Parameswaran, N. 1980. Some remarks on the nomenclature of fibres, sclereids and fibre-sclereids in the secondary phloem of trees. IAWA Bulletin 1: 130-132.

Record, S.J. \& Hess, R.W. 1942. American timbers of the family Lauraceae. Tropical Woods 69: 7-33.

Record, S.J. \& Mell, C.D. 1924. Timbers of Tropical America New Haven. Yale University.

Richter, H.G. 1981 Wood and bark anatomy of Lauraceae I. Aniba Aublet. IAWA Bulletin 2: 79-87.

Richter, H.G.; Mazzoni-Viveiros, S.C.; Alves, E.S.; Luchi, A.E. \& Costa, 
C.G. 1996. Padronização de critérios para a descrição anatômica da casca: lista de características e glossário de termos. Revista do Instituto Florestal e IF Série Registros 16: 1-25.

Rizzini, C.T. 1971. Plantas do Brasil: Árvores e Madeiras Úteis do Brasil: Manual de Dendrologia Brasileira. São Paulo, Edgar Blücher/EDUSP.

Rohwer, J.G. 1993. Lauraceae (Nectandra). Flora Neotropica Monograph 60: 1-332.

Rosayro, R.A. 1953. Field characters in the Identification of Tropical Forest Trees. Emp. For. Rev. 32: 124-141.

Roth, I. \& Giménez de Bolsón, A.M. 1997. Argentine Chaco Forests. Dendrology, tree structure, an economic uso. 1. The semi-arid Chaco. Encyclopedia of plant anatomy; Bd. XIV. Teil 5. Berlín, Gebrüder Borntraeger.

Roth, I. 1969. Características estructurales de la corteza de árboles tropicales en zonas húmedas. Darwiniana 15: 115-127.

Roth, I. 1981. Structural patterns of tropical barks. Handbuch der Pflanzen Anatomie. Band IX. Teil 3. Berlín, Gebrüder Borntraeger.

Santos, M. \& Oliveira, P.L. 1988. Aspectos anatômicos da lâmina foliar de Ocotea porosa (Nees) et Mart. ex Nees) J. Angely (Lauraceae). Insula 18: 3-22.

Sass, J.E. 1951. Botanical microtechnique. 2. ed. Iowa, State College. Soffiatti, P. \& Angyalossy-Alfonso, V. 1999. Estudo anatômico comparativo do lenho e da casca de duas espécies de Eugenia L. (Myrtaceae). Revista Brasileira de Botânica 22: 175-184. Stevens, W.C. 1916. Plant anatomy. London, J. \& A. Churchill.

Teixeira, S.P. \& Gabrielli, A.C. 2000. Anatomia do eixo vegetativo de Dahlstedtia pinnata (Benth.) Malme e D. pentaphylla (Taub.) Burk. (Leguminosae, Papilionoideae). Revista Brasileira de Botânica 23: 1-11.

Trockenbrodt, M. \& Parameswaran, N. 1986. A contribution to the taxonomy of the genus Inga Scop. (Mimosaceae) based on the anatomy of the secondary phloem. IAWA Bulletin 7: $62-71$.

Trockenbrodt, M. 1990. Survey and discussion of the terminology used in bark anatomy. IAWA Bulletin 11: 141-166.

Van Wyk, A.E. 1985. The genus Eugenia (Myrtaceae) in Southern Africa: Structure and taxonomic value of bark. South African Journal of Botany 51: 157-180.

Van der Werff, H. 1991. A key to the genera of Lauraceae in the New World. Annals of the Missouri Botanical Garden 78 : 377-387.

Van der Werff, H. \& Richter, H.G. 1996. Toward an improved classification of Lauraceae. Annals of the Missouri Botanical Garden 83: 409-418.

Vattimo, I. 1968. Citomorfologia das folhas das espécies conhecidas de pau-rosa. II - Estudo da epiderme e da nervura central de Aniba rosaeodora Ducke (Lauraceae). Revista Brasileira de Biologia 28: 161-165.

Wood, G.H.S. 1952. Bark as mean of tree identification. Journal of the Oxford University Forest Society 6: 15-27.

Yunus, M.; Yunus, D. \& Iqbal, M. 1990. Systematic bark morphology of some tropical trees. Botanical Journal of the Linnean Society 103: $367-377$. 